3. Wanicki JL, Barrett W, Saghafi 0 , et al. Prehospital ketamine for excited delirium in the setting of acute drug intoxication. In: Toxicology Clinical. New York, NY: Informa Healthcare, 2014:685-6.

4. Helmer J, Acker J, Deakin J, Johnston $T$. Canadian paramedic experience with intramuscular ketamine for extreme agitation: A quality improvement initiative. Australasian Journal of Paramedicine. 2020;17.
5. Scaggs TR, Glass DM, Hutchcraft MG, Weir WB. Prehospital Ketamine is a Safe and Effective Treatment for Excited Delirium in a Community Hospital Based EMS System. Prehosp Disaster med. 2016;31(5):563-569.

6. Ruttenber AJ, Lawler-Heavner J, Yin $M$, et al. Fatal excited delirium following cocaine use: epidemiologic findings provide new evidence for mechanisms of cocaine toxicity. J Forensic Sci. $1997 ; 42(1): 25-31$

\title{
KHẢO SÁT TỶ LÊ STAPHYLOCOCCUS AUREUS ĐỀ KHÁNG METHICILLIN (MRSA) VÀ HIỆU QUẢ PHỐI HỢP KHÁNG SINH VANCOMYCIN VỚI CEFEPIME/GENTAMICIN TRÊN CÁC CHỦNG MRSA PHÂN LẬP TẠI BỆNH VIỆN ĐA KHOA BẠC LIÊU
}

Bùi Phát Đạt ${ }^{1}$, Lê Văn Chương ${ }^{2,3}$, Ngô Quốc Đạt ${ }^{2}$,

\section{TÓM TẮT}

Đặt vấn đê: Staphylococcus aureus (S. aureus) đề kháng methicillin (MRSA) được Trung tâm kiểm soát và phòng ngừa bệnh tật Hoa Kỳ liệt kê là một trong những: "Mối đe dọa về kháng thuổc kháng sinh ở Hoa Kỳ" vì mức độ nghiêm trọng và đăc tính đa kháng thuốc. Liệu pháp phối hợp kháng sinh điêuu trị MRSA hiện nay đang chỉ ra nhiều hứa hẹn. Muc tiều: Xác định tỷ lệ MRSA và khảo sát hiệu quả phối hợp kháng sinh giữa vancomycin với cefepime, vancomycin với gentamicin trên các chủng MRSA. Phương pháp nghiên cứu: Từ 125 chủng $\mathrm{S}$. aureus được định danh và làm kháng sinh đồ bằng máy tự động Vitek2 Compact, thu thâp được 111 chủng MRSA bằng MIC (nồng độ ức chể tối thiểu) cefoxitin screen có sẵn trong card AST P592. Phối hợp kháng sinh giữa vancomycin với cefepime trên 111 chủng MRSA; giữa vancomycin và gentamicin trên 53 chủng MRSA bằng phương pháp vi pha loãng (checkerboard). Kết quả: Tỷ lể MRSA chiếm $88,8 \%$. MRSA phân bố nhiều nhất ở bệnh phẩm mủ $(61,3 \%)$, dịch $(22,5 \%)$, đàm $(10,8 \%)$ và máu $(5,4 \%)$. Dựa vào chỉ số FIC (nồng độ ức chế phân đoạn), phối hợp kháng sinh vancomycin với cefepime cho kết quả hiệp đông (45\%), cộng (51,3\%), độc lập $(3,6 \%)$ và không có đối kháng. Vancomycin với gentamicin cho kết quả hiệp đồng $(39,6 \%)$, cộng $(58,5 \%)$, độc lập $(1,9 \%)$ và không có đối kháng. Kêt́ luận: Tý lệ MRSA khá cao được ghi nhận tại Bệnh viện Đa khoa Bạc Liêu. Phối hợp kháng sinh vancomycin

${ }^{1}$ Bệnh viện Đa khoa Bạc Liêu

2Đäi hoc Y Dướ TPHCM

${ }^{3}$ Trung tâm Kiểm chuẩn Chất lượng Xét nghiệm Y học, Đại hoc Y Dước TPHCM

${ }^{4}$ Bênh viên Đai hoc Y Dướ TPHCM

Chịu trách nhiệm chính: Huỳnh Minh Tuấn

Email: huynhtuan@ump.edu.vn

Ngày nhận bài: 23.8.2021

Ngày phản biên khoa hoc: 18.10.2021

Ngày duyệt bài: 28.10.2021
Hồ Ngọc Hương1, Huỳnh Minh Tuấn ${ }^{2,4}$ với cefepime, vancomycin với gentamicin cho hiệu quả hiệp đồng và cộng hợp cao trên các chủng MRSA. Kết quả nghiên cứu là cớ sở cho việc cân nhắc lựa chọn phối hợp kháng sinh của bác sĩ và là tiền đề nghiển cứu hiệu quả phối hợp kháng sinh trên lâm sàng.

Tưं khoá: S. aureus, MRSA, phối hợp kháng sinh, vancomycin, checkerboard.

\section{SUMMARY}

PREVALENCE OF METHICILLIN RESITANCE S. AUREUS AND EFFICACY OF ANTIBIOTIC COMBINATION BETWEEN VANCOMYCIN AND CEFEPIME OR GENTAMICIN AGAINST MRSA ISOLATED FROM BAC LIEU GENERAL HOSPITAL

Background: Methicillin resistant $S$. aureus (MRSA) is listed by Centers for Disease Control and Prevention as one of the: "Antibiotic Resistance Threats in the United States" because of its severity and multidrug resistance. Antibiotic combination treatment for MRSA infections has been shown promising treatment. Objective: To determine percentages detection of MRSA and efficacy of antibiotic combination between vancomycin and cefepime or gentamicin against MRSA strains. Methods: From 125 strains of S. aureus that were identified and performed routine antibiotic susceptibility testing by automated machine (Vitek2 Compact), 111 MRSA strains were determined by MIC (minimum inhibitory concentration) cefoxitin screen available in card AST-P592. In vitro antibiotic combination between vancomycin and cefepime on 111 MRSA strains; vancomycin and gentamicin on 53 MRSA strains by microdilution (checkerboard) method. Results: Prevalence of MRSA is $88.8 \%$. MRSA was most widely distributed in pus $(61.3 \%)$, fluid $(22.5 \%)$, sputum $(10.8 \%)$ and blood (5.4\%). Based on the FIC (Fractional Inhibitory Concentration) index, vancomycin-cefepime combination showed synergism $(45 \%)$, additive $(51.3 \%)$, independent $(3.6 \%)$ and no antagonism. Vancomycin-gentamicin combination 
showed synergism (39.6\%), additive (58.5\%), independent $(1.9 \%)$ and no antagonism. Conclusion: High rate of MRSA was recorded at Bac Lieu General Hospital. Antibiotic combination between vancomycin and cefepime or gentamicin for high synergistic and additive effect against MRSA strains. The research results are the basis for doctors to consider the choice of antibiotic combination and the premise to study the effectiveness of antibiotic combination in clinical practice.

Key words; S. aureus, MRSA, combination antibiotics, vancomycin, checkerboard.

\section{I. ĐẶT VẤN ĐỀ}

S. aureus là loại vi khuẩn có khả năng tồn tại lâu trong điều kiện môi trường khắc nghiệt, cư trú trên màng nhầy, da, gây bệnh cơ hội nghiêm trong thông qua trung gian độc tố và gây nhiễm trùng xâm lấn sinh mủ ở người.

S. aureus đề kháng methicillin hay các penicillin $\mathrm{M}$ bằng cách thay đổi cấu trúc Penicillin binding protein (PBP) thành PBP2a không còn ái lực với methicillin nữa. Sự hiện diện của PBP2a làm cho các chủng MRSA kháng toàn bộ họ kháng sinh (KS) $\beta$-lactam, ngoại trừ những $\mathrm{KS}$ cephalosporin thế hệ 5 như ceftobiprole [1].

Kháng sinh điều trị tiêu chuẩn cho MRSA hiện nay vẫn là vancomycin, tuy nhiên bất lợi khi sử dụng KS vancomycin có thể kể đến là thầm nhập mô kém, tiêu diệt vi khuẩn chậm [4]. Mặt khác, chỉ định KS vancomycin đang phải đối diện với một thách thức mới, không phải do xuất hiện đề kháng vancomycin mà là do MIC của vancomycin đối với S. aureus bị tăng vượt quá $1,5 \mu \mathrm{g} / \mathrm{mL}$ gây thất bại điều trị vancomycin trên lâm sàng [1].

Hiện nay, trên thế giới có nhiều nghiên cứu về giải pháp thử nghiệm phối hợp KS trong phòng thí nghiệm với các trường hợp nhiễm khuẩn nặng do $S$. aureus đề kháng methicillin [2], [4], [5]. Tại nước ta hiện còn ít nghiên cứu về phối hợp KS trong phòng thí nghiếm trên vi khuẩn Gram dương nói chung và đặc biệt là $S$. aureus đề kháng methicillin. Vì vậy chúng tôi thực hiện nghiên cứu này, với mục tiêu: "Khảo sát hiệu quả phối hợp kháng sinh giữa vancomycin với cefepime, vancomycin với gentamicin trên $S$. aureus đề kháng methicillin bằng phương pháp vi pha loãng".

\section{II. ĐỐI TƯỢNG VÀ PHƯƠNG PHÁP NGHIÊN CỨU \\ 2.1. Đối tượng nghiên cứu \\ Dân số mục tiêu: chủng S. aureus phân lập} được từ các loại bệnh phẩm (mủ, đàm/dịch rửa phế quản, máu, nước tiểu và các dịch cơ thể khác) tại Khoa Xét nghiệm - Bệnh viện Đa khoa Bac Liêu từ tháng 11/2020 đến tháng 06/2021.

\subsection{Phương pháp nghiên cứu}

Thiêt kế nghiên cứu: nghiên cứu cắt ngang.

Các bước tiến hành: Phân lập S. aureus từ các bệnh phẩm; xác định MRSA (bằng cách sử dụng giếng KS cefoxittin screen có sẵn trong card AST - P592). Xác định đặc tính kháng thuốc bằng máy Vitek2 Compact của hãng bioMérieux - Pháp theo tiêu chuẩn của Viện tiêu chuẩn lâm sàng và xét nghiệm Hoa Kỳ (CLSI) 2021 [3].

Chuẩn bị KS thử nghiệm (được kiểm soát chất lượng KS trên các chủng chuẩn ATCC theo tiêu chuẩn CLSI 2021 [3]; các loại KS sử dụng của hãng Sigma - Aldrich). Thử nghiệm phối hợp KS vancomycin với cefepime, vancomcyin với gentamicin trên MRSA bằng phương pháp vi pha loãng (checkerboard) tại Bộ môn Vi sinh - Ký sinh, Khoa Y (Đại học Y Dược Thành phố Hồ Chí Minh).

Sơ lược về phương pháp vi pha loãng (checkerboard): là kỹ thuật xét nghiệm định lượng phối hợp $K S$, phối hợp hai $K S A$ và $B$ với từng nồng độ khác nhau trển bản nhưa 96 giếng. Kết quả phối hợp KS được đánh giá thông qua chỉ số FIC, được tính như sau:

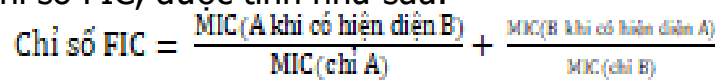

Kết quả phối hợp KS được đánh giá dựa trên bảng dưới đây:

Bảng 1: Tiêu chuẩn đánh giá phối hợp hai kháng sinh

\begin{tabular}{|c|c|c|c|}
\hline Hiệp đồng & Cộng & Độc lập & Đối kháng \\
\hline FIC $\leq 0,5$ & $\begin{array}{c}0,5<\text { FIC } \\
\leq 1\end{array}$ & $1<$ FIC $<4$ & FIC $\geq 4$ \\
\hline
\end{tabular}

Phương pháp xử lý số liệu: sử dụng phần mềm MS. Excel 2016, phân tích số liệu bằng STATA 14.0

Vấn đề y đức: được chấp thuận bởi Hội đồng Đạo đức trong nghiên cứu $Y$ sinh học, Đại học $Y$ Dược TPHCM (quyết định số 754/HĐĐĐ-ĐHYD ngày $22 / 10 / 2020$ ).

\section{KẾT QUẢ NGHIÊN CỨU VÀ BÀN LUÂNN \\ 3.1 Tỷ lệ MRSA}

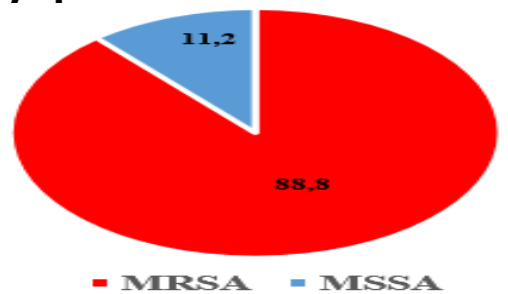

Biếu đồ 1: Tỷ lệ MRSA của S. aureus

Nhìn vào biểu đồ $\dot{1}$, với 125 chủng $S$. aureus phân lập được có 111 chủng MRSA $(88,8 \%)$ và 14 chủng MSSA (11,2\%).

3.2. Sự phân bố MRSA trong bệnh phẩm

Bảng 2: Tỷ lệ MRSA phân bố trên các loại 
bệnh phẩm

\begin{tabular}{|c|c|}
\hline Bệnh phấm & n (\%) \\
\hline Mủ & $68(61,3)$ \\
\hline Dịch & $25(22,5)$ \\
\hline Đàm & $12(10,8)$ \\
\hline Máu & $6(5,4)$ \\
\hline
\end{tabular}

Dựa vào bảng 2 , ta thấy tỷ lệ $M R S A$ phân lập nhiêu nhất ở bệnh phẩm mủ $(61,3 \%)$, cao hởn nhiều so với các bệnh phẩm khác như dịch $(22,5 \%)$, đàm $(10,8 \%)$ và máu $(5,4 \%)$.

3.3. Kết quả phối hợp kháng sinh giữa vancomycin với cefepime; vancomycin với gentamicin.

Bảng 3: Kết quả phôi hợp kháng sinh giữa vancomycin với cefepime; vancomycin với gentamicin

\begin{tabular}{|c|c|c|}
\hline $\begin{array}{c}\text { Kết quả } \\
\text { phối hợp }\end{array}$ & VAN + FEP & VAN + GEN \\
\cline { 2 - 3 } Hiệp đồng & $50(45)$ & n (\%) \\
\hline Cộng & $57(51,3)$ & $21(39,6)$ \\
\hline Độ̣ lập & $4(3,7)$ & $1(1,9)$ \\
\hline Đối kháng & $0(0)$ & $0(0)$ \\
\hline
\end{tabular}

(VAN: vancomycin; FEP: cefepime; GEN: gentamicin)

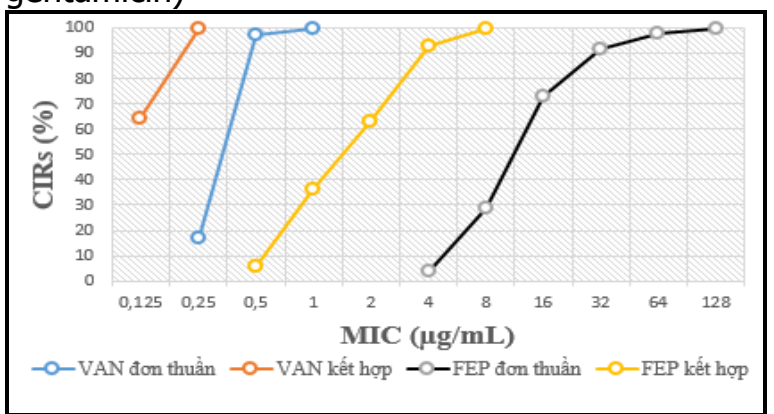

Biểu đồ 2: Tỷ lệ ức chế tích luỹ (CIRs) của vancomycin, cefepime đơn thuần và phối hợp trên 111 chüng MRSA

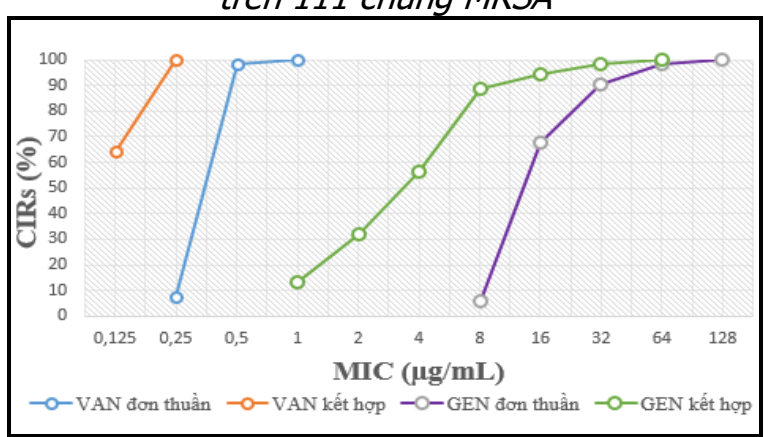

Biểu đồ 3: Tý lệ ức chế tích luỹ (CIRs) của vancomycin, gentamicin đơn thuần và phối hợp trên 53 chủng MRSA

Sau khi thực hiện phối hợp KS giữa vancomycin với cefepime bằng phương pháp vi pha loãng (checkerboard) trên 111 chủng MRSA, dựa trên chỉ số FIC cho kết quả hiệp đồng
(45\%), cộng (51,3\%), độc lập (3,7\%) và không có chủng đối kháng. Phối hợp giữa vancomycin và gentamicin trên 53 chủng MRSA (50 chủng kháng và 3 chủng trung gian với gentamicin) cho kết quả hiệp đồng (39,6\%), cộng (58,5\%), độc lập $(1,9 \%)$ và không có chủng đối kháng. Thông qua kiểm định Mann - Whitney, ta thấy có sự khác biệt có ý nghĩa giữa hiệu quả của việc phối hợp KS vancomycin với cefepime/gentamicin so với sử dụng $K S$ vancomycin riêng lẻ $(p<0,05)$.

Ngoài ra, xét về mức độ giảm MIC của vancomycin và cefepime khi phối hợp so với sử dụng đơn thuần ta thấy MIC range (khoảng giá trị MIC từ nhỏ nhất cho đến lớn nhất) của vancomycin giảm từ $(0,25-1 \mu \mathrm{g} / \mathrm{mL})$ xuống còn $(0,125-0,25 \mu \mathrm{g} / \mathrm{mL}) ;$ MIC range của cefepime giảm từ $(4-128 \mu \mathrm{g} / \mathrm{mL})$ xuống còn $(0,5-8 \mu \mathrm{g} / \mathrm{mL})$. Tương tự, khi phối hợp vancomycin với gentamicin, MIC range của vancomycin cũng giảm từ $(0,25-1 \mu \mathrm{g} / \mathrm{mL})$ xuống còn $(0,125-0,25$ $\mu \mathrm{g} / \mathrm{mL}$ ); MIC range của gentamicin giảm từ (8$128 \mu \mathrm{g} / \mathrm{mL}$ ) xuống còn (1-64 $\mu \mathrm{g} / \mathrm{mL})$.

Bàn luận: nhìn vào biểu đồ 2 cho thấy, đường cong ức chế tích luỹ của vancomycin và cefepime khi phối hợp di chuyển rõ rệt sang bên trái so với khi sử dụng KS đơn thuần nghĩa là giá trị MIC có giảm đi rõ khi phối hợp 2 loại KS. Điều này, tương đồng với nghiên cứu của Drago L. và cộng sự (2007) khi phối hợp giữa vancomycin với cefotaxime (cũng là một KS thuộc nhóm cephalosporin) [5]. Tác dụng hiệp đồng giữa vancomycin và cefepime có thể giải thích bằng hiện tượng "seesaw" làm giảm MIC và diệt khuẩn khi phối hợp vancomycin với kháng sinh $\beta$ lactam. Kháng sinh $\beta$-lactam ức chế tổng hợp vách, làm mỏng thành tế bào tạo điều kiện cho vancomycin gẳn và ức chế đích tác động, vancomycin làm giảm biểu hiện gen mecA, tăng tác dụng của kháng sinh $\beta$-lactam [7].

Ngoài ra, ở biểu đồ 3 cũng cho thây đường cong ức chế tích luỹ của vancomycin và gentamicin khi phối hợp di chuyển rõ rệt sang bên trái so với khi sử dụng KS đơn thuần, nghĩa là giá trị MIC có giảm đi rõ khi phối hợp 2 loại KS. Kết quả nghiên cứu của chúng tôi hoàn toàn tương đồng với nghiên cứu của Lutfiye Mulazimoglu và cộng sự ở Hoa Kỳ năm 1996 [6], khi phối hợp vancomycin với gentamicin trên các chủng MRSA bằng phương pháp theo dõi thời gian diệt khuẩn (cũng là một trong những kỹ thuật phối hợp KS). Điều này cũng phù hợp với nguyên tắc sử dụng KS khi phối hợp, KS glycopeptid cụ thể là vancomycin ức chế thành lập lớp peptidoglycan của vách tế bào vi khuẩn 
tạo điều kiện thuận lợi cho KS aminoglycosides, cụ thể là gentamicin xâm nhập vào tế bào vi khuẩn ức chế tổng hợp protein dẫn đến vi khuẩn bi tiêu diêt.

Bảng 4: Giảm MIC có ý nghĩa của gentamicin khi có sư phối hợp với vancomycin

\begin{tabular}{|c|c|}
\hline MIC của GEN khi có VAN & n (\%) \\
\hline $\mathrm{R} \rightarrow \mathrm{S}$ & $27(50,9)$ \\
$\mathrm{R} \rightarrow \mathrm{I}$ & $17(32,1)$ \\
$\mathrm{I} \rightarrow \mathrm{S}$ & $3(5,7)$ \\
\hline
\end{tabular}

(R: kháng, I: trung gian, S: nhạy)

Nghiên cứu chọn 53 chủng MRSA dùng để phối hợp vancomycin với gentamicin (50 chủng kháng và 3 chủng trung gian với gentamicin), nghĩa là tỷ lệ kháng gentamicin trước phối hợp là 50/53 (94,3\%); sau khi phối hợp với vancomycin chỉ có 6 chủng kháng, 17 chủng trung gian và 30 chủng nhạy, với tỷ lệ kháng gentamicin còn $6 / 53$ $(8,8 \%)$.

\section{KẾT LUÂ̂N}

Qua kết quả nghiên cứu, tỷ lệ MRSA của 125 chủng S. aureus phân lập được tại Bệnh viện Đa khoa Bạc Liêu đang ở mức cao $(88,8 \%)$; đồng thời thực hiện phối hợp KS trên toàn bộ chủng MRSA (vancomycin phối hợp cefepime) và 53 chủng MRSA (vancomycin phối hợp gentamicin) nghiên cứu rút ra được tỷ lệ MRSA phân lập nhiều nhất ở bệnh phẩm mủ $(61,3 \%)$, kế đến là dịch $(22,5 \%)$, đàm $(10,8 \%)$ và ít nhất là bệnh phẩm máu $(5,4 \%)$.

Phối hợ KS vancomycin với cefepime cho hiệu quả tốt hơn khi sử dụng đơn KS vancomycin trển 111 chủng MRSA với tỷ lệ hiệp đồng là 45\%, cộng (51,3\%), độc lập (3,6\%) và không có tỷ lệ đối kháng.

Phối hợp KS vancomycin với gentamicin cho hiệu quả tốt hơn khi sử dụng đơn KS vancomycin hoặc KS gentamicin trên 53 chủng MRSA với tỷ lệ hiệp đồng là 39,6\%, cộng (58,5\%), độc lập $(1,9 \%)$ và không có tỷ lệ đối kháng.

\section{TÀI LIÊU THAM KHẢO}

1. Phạm Hùng Vân, Phạm Thái Bình (2013), Kháng sinh - Đề kháng kháng sinh - Kỹ thuật kháng sinh đồ, Các vấn đề cơ bản thường gặp, Nhà xuất bản Y học Hà Nội.

2. Bhise $K$, Sau $S$, Kebriaei $R$, et al (2018), "Combination of Vancomycin and Cefazolin Lipid Nanoparticles for Overcoming Antibiotic Resistance of MRSA", Materials (Basel), 11 (7), pp. 1996-1944 (Print).

3. Clinical and Laboratory Standards Institute (2021), "Perormance Standards for Antimicrobial Susceptibility Testing", M100S31,31st Edition, Clinical and Laboratory Standards Institute.

4. Davis JS, Van Hal S, Tong SY (2015), "Combination antibiotic treatment of serious methicillin-resistant Staphylococcus aureus infections", Semin Respir Crit Care Med, 36 (1), pp. 3-16.

5. Drago L, De Vecchi E, Nicola L, Gismondo MR (2007), "In vitro evaluation of antibiotics' combinations for empirical therapy of suspected methicillin resistant Staphylococcus aureus severe respiratory infections", BMC Infect Dis, 7 (1), pp.1-7.

6. Mulazimoglu $L$, Drenning SD, Muder RR (1996), "Vancomycin-gentamicin synergism revisited: effect of gentamicin susceptibility of methicillin-resistant Staphylococcus aureus", Antimicrob Agents Chemother, 40 (6), pp. 1534-1535.

7. Ortwine JK, Werth BJ, Sakoulas G, Rybak MJ (2013), "Reduced glycopeptide and lipopeptide susceptibility in Staphylococcus aureus and the "seesaw effect": Taking advantage of the back door left open?", Drug Resist Updat, 16 (3-5), pp. 73-79.

\section{NGHIÊN CỨU KẾT QUẢ PHẪU THUÂ̂T CẮT TỬ CUNG HOÀN TOÀN QUA NộI SOI DO U XƠ TỬ CUNG TẠI BỆNH VIỆN THANH NHÀN NĂM 2020}

\section{TÓM TẮT}

Nghiên cứu nhằm mục tiêu mô tả đặc điểm lâm sàng và cận lâm của các bệnh nhân u xơ tử cung được cắt tử cung hoàn toàn qua nội soi tại Bệnh viện Thanh Nhàn từ tháng $1 / 2019$ đến tháng $12 / 2020$ và đánh giá kết quả phương pháp cắt tử cung hoàn toàn qua nội

\footnotetext{
${ }^{1}$ Bệnh viện Thanh Nhàn.

²Bệnh viện Sản Trung Ương.

Chịu trách nhiệm chính: Nguyễn Thị Thu

Email: Dieuthu8587@gmail.com

Ngày nhận bài: 24.8.2021

Ngày phản biện khoa học: 19.10.2021

Ngày duyệt bài: 29.10.2021
}

\section{Nguyễn Thị Thu', Đào Thị Hoa ${ }^{2}$}

soi ở nhóm bệnh nhân trên. Chúng tôi tiến hành nghiên cứu mô tả cắt ngang trên 108 bệnh nhân u xơ tứ cung được cắt tử cung hoàn toàn qua nội soi tại khoa sản Bệnh viện Thanh Nhàn. Kết quả nghiên cứu cho thấy: Độ tuổi trung bình của đối tượng nghiên cứu là $46,5 \pm 3,7$ (tuổi), thời gian phấu thuất trung bình là $78,6 \pm 12,8$ phút, trọng lượng tử cung càng lớn thì thời gian phấu thuật càng dài và kích thước tử cung càng lớn thì lượng máu mất các nhiều $(p<0,05)$.

Tư khóa: u xơ tử cung, phấu thuật nội soi, cắt tử cung hoàn toàn.

\section{SUMMARY \\ RESEARCH ON RESULTS OF COMPLETE LAPAROSCOPIC HYSTERECTOMY DUE TO}

